\title{
OS EFEITOS DA PANDEMIA NA EDUCAÇÃO DE CRIANÇAS E ADOLESCENTES NO BRASIL
}

\section{THE EFFECTS OF PANDEMIC ON CHILD AND ADOLESCENT EDUCATION IN BRAZIL}

\section{Michel Canuto de Sena* Graciele da Silva Ady Faria da Silva ${ }^{* \star *}$ Paulo Roberto Haidamus de Oliveira Bastos ${ }^{\star \star \star}$}

Resumo: O objetivo do presente artigo é analisar os efeitos da pandemia na educação de crianças e adolescentes no Brasil. Para tanto, a metodologia utilizada foi a revisão descritiva, realizada a partir de artigos científicos completos disponíveis em plataformas de literatura Latino-americana e do Caribe (LILACS) e Biblioteca Eletrônica de Periódicos Científicos Brasileiros (SciELO), acessados por intermédio da Biblioteca Virtual em Saúde (BVS). Os resultados da pesquisa demonstram que a pandemia da COVID-19 trouxe impactos negativos transversais e assimétricos em todo o campo da Educação, potencializando 0 aumento da desigualdade socioeconômica e educacional, ampliado no contexto de isolamento social, forçando os profissionais da educação a encontrar alternativas tecnológicas para transmitir os conteúdos aos alunos.

Palavras-chave: Educação. Pandemia. Criança. Adolescente.

Abstract: The purpose of this article is to analyze the effects of the pandemic on the education of children and adolescents in Brazil. To this end, the methodology used was the descriptive review, carried out from complete scientific articles available on platforms of Latin American and Caribbean literature (LILACS) and Electronic Library of Brazilian Scientific Journals (SciELO), accessed through the Virtual Library at Health (VHL). The results of the research demonstrate that the COVID-19 pandemic brought transversal and asymmetric negative impacts across the field of Education, enhancing the increase in socioeconomic and educational inequality, amplified in the context of social isolation, forcing education professionals to find technological alternatives to transmit the contents to the students.

\footnotetext{
* Doutorando pelo Programa de Pós-graduação em Saúde e Desenvolvimento na Região CentroOeste da Universidade Federal de Mato Grosso do Sul. Professor de Direito Civil na Faculdade de Direito Prof. Nelson Trad - FADIR/UFMS. Faz parte da Academia Paulista de Direito (SP). Bolsista CAPES. E-mail: canuto.fadir.ufms@gmail.com.

${ }^{* *}$ Mestranda no Programa de Pós-graduação em Saúde e Desenvolvimento na Região Centro-Oeste da Universidade Federal de Mato Grosso do Sul. Bolsista CAPES. E-mail: gracieleesilva@yahoo.com. ${ }^{* * *}$ Mestrando no Programa de Pós-graduação em Saúde e Desenvolvimento na Região Centro-Oeste da Universidade Federal de Mato Grosso do Sul. E-mail: adyfaria@hotmail.com.

${ }^{* * * *}$ Doutorado em Educação pela Pontifícia Universidade Católica de São Paulo. Pesquisador permanente do Programa de Pós-Graduação Stricto Sensu em Saúde e Desenvolvimento na Região Centro-Oeste, da Faculdade de Medicina, da Universidade Federal de Mato Grosso do Sul. E-mail: phaidamus43@gmail.com.
} 
Keywords: Education. Pandemic. Kid. Adolescent. 


\section{INTRODUÇÃO}

No mês de dezembro de 2019, na cidade de Wuhan, na China, ocorria o primeiro caso de uma doença respiratória causada pelo Coronavírus, uma síndrome respiratória aguda grave. Em um primeiro momento, a sociedade do mundo inteiro pensava ser um problema local, mas em 11 de março de 2020, a contaminação passa a mostrar os seus efeitos na Europa e nas Américas.

Em território brasileiro, o primeiro caso foi identificado no dia 25 de fevereiro de 2020. A Organização Mundial de Saúde (OMS) indicou que se tratava de uma pandemia e a medida cabível seria o isolamento social com a intenção de diminuir a propagação e salvar vidas.

A Organização Mundial da Saúde (OMS) declarou que a Covid-19, doença causada pelo novo coronavírus foi classificada como uma pandemia. Assim, a pandemia pode ser definida como uma disseminação mundial de uma nova doença que afeta uma região e se espalha por diferentes continentes, potencializando a contaminação de pessoa para pessoa.

Os efeitos da pandemia do novo coronavírus configuram-se como uma crise mundial que afeta a economia, educação, política entre outros setores. Dentre os setores que foram mais atingidos se encontram o fechamento das escolas, cujo objetivo é reduzir o contato entre pessoas e salvar vidas.

Diante dessa nova realidade, a educação teve de ser adaptada e os alunos passaram a ter aula na modalidade on-line, assistidas de suas casas. Essa nova modalidade de aulas on-line causou impacto na produtividade dos pais, na vida social e no aprendizado de crianças e de adolescentes, e se colocou como a melhor opção para dar continuidade às aulas interrompidas por todo o país.

No Brasil, o impacto do aprendizado em diferentes níveis ainda não pode ser mensurado, mas apresenta evidências sobre a dificuldade de avaliar o aprendizado dos alunos afetados pela pandemia. Com as aulas remotas e na falta de critérios específicos, alguns Estados optaram por aprovar os alunos. Isso representa a fragilidade do ensino, pois se percebe que os professores não receberam a qualificação adequada em relação aos meios virtuais, tampouco todos os alunos possuem acesso à internet. 
Desse modo, objetiva-se verificar a formação docente no Brasil e os mecanismos de políticas públicas direcionadas as crianças e aos adolescentes no que se refere à educação em período pandêmico.

A metodologia utilizada foi a revisão descritiva, realizada a partir de artigos científicos completos disponíveis em plataformas de literatura Latino-americana e do Caribe (LILACS) e Biblioteca Eletrônica de Periódicos Científicos Brasileiros (SciELO), acessados por intermédio da Biblioteca Virtual em Saúde (BVS), utilizando-se da expressão de busca: educação em período de pandemia, pandemia e ferramentas educacionais, apenas no idioma português por se tratar de uma análise do contexto brasileiro.

Adotaram-se os seguintes critérios: Inclusão: disponibilidade do artigo completo; focalização do local do estudo. Exclusão: artigos completos não disponíveis; artigos repetidos.

O problema da pesquisa é: quais são os prejuízos que as crianças e os adolescentes estão sofrendo com a ausência de sala de aula?

\section{SISTEMA NACIONAL DE EDUCAÇÃO}

N O Sistema Nacional de Educação (SNE) organiza e distribui as funções entre os Municípios, os Estados e a União. Além disso, possui a função de determinar como as três esferas devem atuar para a consolidação da educação brasileira.

A educação é classificada como um direito social na Constituição Federal de 1988 (BRASIL, 1988). No mesmo sentido, o artigo sexto dispõe que são direitos sociais: (I) a educação; (II) o trabalho; (III) o lazer; (IV) a segurança; (V) a previdência social; $(\mathrm{VI})$ a proteção à maternidade e à infância e (VII) a assistência aos desamparados.

Desta feita, a educação é um direito público subjetivo, em outras linhas, o acesso ao ensino fundamental é obrigatório e gratuito. Assim, o não oferecimento do ensino obrigatório pelo Poder Público em suas três esferas resultará em responsabilidade da autoridade competente.

Os municípios atuarão de forma prioritária sobre o ensino fundamental e na educação infantil. Já os Estados e o Distrito Federal nos ensinos fundamental e no 
médio. De acordo com a Lei no 9394 de 1996 (Lei de Diretrizes da Educação Nacional) (BRASIL, 1996), a educação básica pode ser compreendida como infantil, ensino fundamental e ensino médio, podendo ainda ser dividida em modalidades, são elas: educação especial, educação de jovens e adultos, educação profissional, educação indígena e educação do campo (MACHADO; ANDRADE, 2021).

A competência do Sistema Federal é elaborar o Plano Nacional de Educação e assegurar o processo nacional de avaliação sobre o rendimento das escolas em todos os níveis da educação. No caso do Sistema Estadual, cabe assegurar o ensino fundamental e, ainda, oferecer com prioridade o ensino médio. Isso ocorre com o Sistema Municipal que deverá garantir o sistema infantil e atuar na oferta do ensino fundamental (MACHADO; ANDRADE, 2021).

A Lei de Diretrizes e Bases da Educação Brasileira (BRASIL, 1996) possui como pilares a educação, a valorização da diversidade, a flexibilidade, a qualidade e a autonomia, mas esses elementos necessitam de diálogo com o trabalho e com a cidadania. O modelo de educação não pode ser pautado apenas em ensinar e aprender, mas sim sintonizado com as ações de trabalho e como a criança e o adolescente terão acesso ao mercado de trabalho (OLIVEIRA; LIBÂNEO; TOSCHI, 2017).

A educação pode ser entendida como um direito fundamental. Assim, engloba, de forma ampla, os enunciados genéricos, verídicos e corretos, que são formulados com base na Teoria da Multifuncionalidade dos Direitos Fundamentais, cuja origem pode ser encontrada na Teoria dos Quatro Status de Jellinek. Dessa forma, os direitos fundamentais não podem ser restritos a direitos de defesa contra os poderes públicos, mas atuam com diversas funções na ordem jurídica (ALEXY, 2017).

Nesse ínterim, a educação possui diversas vertentes e, nela, deve ocorrer sempre o respeito a dignidade da pessoa humana, a igualdade de direitos, a não discriminação dentro e fora das escolas, a solidariedade e a capacidade de viver em sociedade, inclusive com 0 intuito de evitar os conflitos e a violência escolar (PIOVESAN, 2017).

Por outro lado, existe a necessidade de revisões das políticas educacionais, inclusive sobre as condições salarias dos professores. Além disso, uma estrutura de apoio que possa favorecer o desenvolvimento administrativo da escola, para que os 
discentes, mesmo que em condição de desigualdade, possam buscar um local de conhecimento e confiança (PIOVESAN, 2017).

A Constituição Federal de 1988 (BRASIL, 1988) traz, em seu artigo 205, a educação como direito de todos e dever do Estado e da família, será ela promovida e incentivada em colaboração com a sociedade. Ainda, o ensino deve ser ministrado conforme as seguintes diretrizes:

[...] I - igualdade de condições para o acesso e permanência na escola;

II - liberdade de aprender, ensinar, pesquisar e divulgar o pensamento, a arte e o saber;

III - pluralismo de ideias e de concepções pedagógicas, e coexistência de instituições públicas e privadas de ensino;

IV - gratuidade do ensino público em estabelecimentos oficiais;

V - valorização dos profissionais da educação escolar, garantidos, na forma da lei, planos de carreira, com ingresso exclusivamente por concurso público de provas e títulos, aos das redes públicas; (Redação dada pela Emenda Constitucional no 53 , de 2006)

VI - gestão democrática do ensino público, na forma da lei;

VII - garantia de padrão de qualidade.

VIII - piso salarial profissional nacional para os profissionais da educação escolar pública, nos termos de lei federal. (Incluído pela Emenda Constitucional $\mathrm{n}^{\circ}$ 53, de 2006)

IX - garantia do direito à educação e à aprendizagem ao longo da vida. (Incluído pela Emenda Constitucional oㅜ 108, de 2020). (BRASIL, 1988, p. 1).

Nesse sentido, a universalização do ensino é um dos pontos elementares do sistema educacional, pois atua na erradicação do analfabetismo nos países em que foi implantado. Por outro lado, o Brasil não se encontra entre os países selecionados, mas se levam em consideração alguns dos aspectos que impediram a organização do sistema nacional de educação em terras nacionais.

Vale destacar também os aspectos da liberdade de aprender, ensinar, pesquisar e divulgar o conhecimento. Esse pluralismo de ideias deve existir tanto em instituições públicas como privadas, com o intuito de facilitar a aprendizagem de crianças e de adolescentes.

Além do sistema de educação nacional, a formação de docentes deve ser levada em consideração. Deve-se considerar que a educação por meios remotos (Internet) necessita ser adotada por uma abordagem ativa, evitando-se assim, a evasão escolar em tempos de pandemia. 


\subsection{Formação de docentes no Brasil}

As transformações da sociedade, ao atingirem o contexto escolar, fazem que a escola se adapte ao novo padrão imposto pela própria sociedade. Isso reflete na formação de docentes que necessitam superar o individualismo disciplinar para articular a inter-relação de diversas áreas no processo ensino-aprendizagem.

A formação deve estar ancorada na articulação teórica, na prática e na formação do professor, de modo a superar dicotomias e fragmentações vividas. Desse modo, a interdisciplinaridade na formação do docente permite que ele desenvolva maior capacidade de interação e aceitação de novos conhecimentos, ampliando, assim, novas técnicas adequadas à realidade vivenciada em sala de aula ou em ambiente virtual.

Para que isso se efetive, a formação em educação deve garantir o acesso a todos, inclusive a utilização de novas tecnologias, por exemplo: ambientes virtuais de comunicação que garantem que o conhecimento chegue até o discente e ocorra a compreensão dos princípios científicos que são transmitidos (SAVIANI, 2010).

Aponta-se, ainda, a necessidade do desenvolvimento na educação com mudanças na formação curricular do professor, seguidas de debates sobre a ética profissional no exercício da docência, requerendo uma evolução do sistema educacional, orientado para o desenvolvimento da competência percebida como alternativa viável para transformações na estrutura organizacional e no funcionamento da escola (CHAVES; AMORIM, 2009).

A construção de novos conhecimentos não pode ser entendida apenas como um fator educacional isolado, pois envolve os fatores sociais, econômicos, morais e políticos. Portanto, a preparação do docente vai além da construção curricular, pois engloba a identidade e a essência que são construídas ao longo de sua jornada, "[...] ensinar não é só transferir conhecimentos", ao nosso ver, o ato de ensinar descontextualizado da práxis não transforma, assim, concorda-se com Freire, quando diz: "Quem ensina aprende ao ensinar e quem aprende ensina ao aprender" (FREIRE, 1969).

Para que ocorram essas transformações, os educadores devem assumir um compromisso ético no exercício de sua prática docente, em outras linhas, possuir domínio de conteúdo e, sobretudo, de como administrar as ocorrências em sala de 
aula, como é o caso da violência escolar. A educação passa por uma restruturação que parte desde a gestão escolar até os conflitos cotidianos vivenciados em ambiente escolar. No mesmo sentido:

[...] A falta de políticas públicas adequadas, más influências, indisciplina no sistema de ensino e a ausência dos pais são alguns dos fatores que podem gerar reflexos positivos ou negativos no desenvolvimento das crianças ou dos adolescentes (SENA et al., 2020, p. 47).

Nesse novo contexto motivado pela pandemia, o docente deve, além de saber transmitir conhecimentos, com domínio do conteúdo, permitindo aos alunos uma reflexão prática, que possibilite investigar e teorizar, neutralizar os conflitos que possam surgir no ambiente de aprendizagem remoto, a título de exemplo: o cyberbullying, que é uma espécie de violência escolar. Assim, poderá mudar seu saber-fazer de um simples transmissor de conhecimentos construídos por especialistas, para uma relação quem constrói e teoriza, a partir do conhecimento (CHAVES; AMORIM, 2009).

De tal modo, a formação interdisciplinar e multidisciplinar amplia a construção dos saberes que são progressivamente adquiridos e constituídos. Nesse contexto, fica evidente a importância da preparação do docente que passa a ter contato com diversos ramos da ciência, o que propicia um melhor desempenho como profissional.

\subsection{Sistema público de ensino brasileiro frente à pandemia do Coronavírus}

Para enfrentar a pandemia do novo coronavírus, utilizaram-se de medidas extraordinárias em busca de conter o avanço da pandemia e, em simultâneo, reduzir o índice de contágio e mortalidade causado pelo vírus. Essas mudanças impactaram na convivência dos indivíduos e na educação.

Nesse novo cenário, as escolas públicas se mantiveram com portões fechados e alunos distantes das salas de aula, obrigando a instituição escolar a se adaptar a novos métodos de ensino, sendo necessário redesenhar algumas metodologias para atender aos alunos. Entretanto, os recursos necessários para pôr em prática essas medidas podem ser substanciais para países com limitações de recursos e economias frágeis, e o fechamento prolongado das escolas pode colocar 
uma pressão significativa nos sistemas educacionais em todo o mundo.

As dificuldades econômicas, advindas com a pandemia, segundo a UNICEF (2020, p. 1-2), "exacerbarão a escassez de financiamento da educação nos próximos anos e afetarão desproporcionalmente os países de baixa renda e as populações marginalizadas cuja demanda por educação pode ser mais frágil”.

\begin{abstract}
[...] A pandemia de Covid-19 aprofundou as desigualdades no sistema educacional brasileiro, no que se refere à infraestrutura sanitária e tecnológica. É o que revela análise do Instituto de Pesquisa Econômica Aplicada (IPEA), com base em dados do Censo Escolar de 2019 sobre escolas federais, estaduais, municipais e particulares. De acordo com a pesquisa, $27 \%$ das escolas dos ensinos fundamental e médio não possuem acesso à internet e $44 \%$ de todas as escolas não são atendidas por rede pública de esgoto. O estudo, intitulado A Infraestrutura Sanitária e Tecnológica das escolas e a retomada das aulas em tempos de Covid-19, utiliza informações sobre matrículas, estabelecimentos e docentes do Censo Escolar 2019, produzido pelo Instituto Nacional de Estudos e Pesquisas Educacionais Anísio Teixeira (Inep). A análise da infraestrutura sanitária considera todas as escolas do país. Sob o aspecto tecnológico, o estudo abrange as instituições de ensinos fundamental e médio (IPEA, 2020, p. 1).
\end{abstract}

No Brasil dados do INEP apontam que das 134.153 escolas de ensino fundamental e médio presentes em todo o território nacional, apenas 34 mil possuem acesso à internet. E destaca que os Estados com maior infraestrutura tecnológica e maior disponibilidade de internet nas escolas são: Distrito Federal (98\%) e Mato Grosso do Sul (98\%), seguidos dos estados de Goiás (97\%), Rio Grande do Sul (97\%) e Santa Catarina (97\%). Já os estados com menor infraestrutura tecnológica são: Acre (27\%), Amazonas (31\%), Maranhão (36\%) e Pará (38\%) (IPEA, 2020, p. 1).

Nesse contexto, fica evidente a disparidade no sistema educacional brasileiro, e, ao mesmo tempo, demostra que determinados municípios possuem crianças de baixa renda estudando com recursos limitados e com o avanço da pandemia questiona-se como ficou o aprendizado dessas crianças e adolescentes, ou seja, fica evidente o profundo desequilíbrio social:

[...] os alunos com menor acesso à internet e a dispositivos, ou aqueles cujos responsáveis têm menor escolaridade e menor disponibilidade para acompanhar as atividades de ensino remotas, são os mais prejudicados. Essas desigualdades não serão resolvidas com o retorno às aulas, uma vez que os protocolos de prevenção preveem o rodízio de alunos, com parte assistindo às aulas presencialmente e parte remotamente. (IPEA, 2020. p. 1). 
No Brasil, a educação está pautada na falta de recursos humanos e materiais, regiões com maior índice de pobreza perpetuam a pior qualidade de ensino e isso fica evidenciado pelo Censo Escolar de 2019 "44\% das escolas não são atendidas por rede de água e esgoto, e 22,4\% não contam nem mesmo com fossas sépticas". Essas condições precárias, realidade de alguns alunos brasileiros complicam ainda mais o retorno as aulas que precisam de maior investimento na infraestrutura (IPEA, 2020, p. 1).

As ações direcionadas a educação devem estar pautadas no aluno, no meio social em que vivem e nas condições que possibilitam o aprendizado. Para isso, as políticas educacionais devem ser direcionadas conforme as necessidades de cada região.

Diante dessa realidade, o Ministério da Educação, em conjunto com as Secretarias de Educação, deve priorizar estratégias para atenuar a desigualdade educacional no Brasil, assegurando infraestrutura e recursos que propiciem melhor aprendizagem, diminuindo os efeitos da crise educacional brasileira. Tendo em vista que a evasão escolar e:

[...] o aumento das desigualdades, muitas vezes como resultado do acesso desigual a métodos alternativos de oferta de aprendizagem. Em determinados contextos, os estudantes também podem ser afetados pela falta de alimentação ou pela exposição à violência, deslocamentos, trabalho infantil e outras condições adversas, com meninas e mulheres sendo particularmente vulneráveis. Além disso, deve-se dar especial atenção aos estudantes de origens vulneráveis, incluindo os que vivem na pobreza, em zonas geograficamente remotas ou em favelas urbanas, provenientes de minorias étnicas, migrantes e refugiados, bem como crianças com deficiências. (UNESCO, 2020, p. 3).

A falta de experiências empíricas relacionadas ao ensino, à aprendizagem e à evasão escolar é decorrente das dinâmicas educacionais existentes que se contrapõem à continuidade remota das atividades educacionais, e isso atrasa todo o processo de alfabetização agravado por não possuir estrutura adequada. A paralisação total dos processos presenciais obrigou os alunos a estudarem de forma virtual, gerando uma ruptura dos processos de ensino e aprendizagem com limitações para a absorção integral dos conteúdos no período de pandemia (SENHORAS, 2020).

Frente ao exposto, utilizar as ferramentas e potencialidades da Internet é uma consequência do mundo globalizado que impõe cada vez mais novas formas e 
práticas pedagógicas de ensino. Ocorre que a pandemia acelerou esse processo de implantação de tecnologias como ferramentas essenciais para o ensino. As experiências no uso das TICs possuem diferentes resultados que dependem das condições de infraestruturas e individuais de acessibilidade.

\section{CONSIDERAÇÕES FINAIS}

Com aumento de casos de Covid-19 pelo mundo, a Organização Mundial da Saúde (OMS) recomendou que fossem adotadas iniciativas de isolamento social e, com essas medidas, o fechamento dos estabelecimentos escolares para conter a transmissão do novo coronavírus. No contexto educacional, precisava-se de alternativas para transmitir conteúdos aos alunos que passariam a ter aulas na modalidade on-line como uma alternativa para aprendizagem durante o período pandêmico.

Por um lado, a pandemia da COVID-19 trouxe impactos negativos transversais e assimétricos em todo o campo da Educação, potencializando o aumento das desigualdades socioeconômica e educacional, ampliado no contexto de isolamento social, forçando os profissionais da educação a encontrar alternativas tecnológicas para transmitir os conteúdos aos alunos. Face a essa busca por ferramenta tecnológica para transmitir conteúdos e, ao mesmo tempo, aproximar o aluno do professor, empresas de tecnologias passaram a disponibilizar diversos aplicativos para interação dos alunos, dentre eles estão Trello, padlet, coggle, mindmup.

Assim, conclui-se que a pandemia da Covid-19 no Brasil criou imensos desafios para professores e alunos que tiveram de se adaptar diante das imensas diversidades existentes no território brasileiro. Dentre vários fatores, a falta de acessibilidade à tecnologia e de conectividade complicam-se diante da falta de domínio dos professores às novas ferramentas tecnológicas.

A estrutura e o desenvolvimento da base curricular na formação de professores não apresentam grandes inovações e avanços que permitam ao licenciando enfrentar o início de uma carreira docente com uma base consistente de conhecimentos disciplinares, de contextos socioeducacionais, práticas com fundamentos e técnicas. De tal modo, iniciativas inovadoras devem representar 
avanços na formação de docentes, visando promover habilidades prático-teórico e permitir desenvolver, criar e ampliar aspectos relativos ao desenvolvimento da educação escolar em suas variadas especificidades.

\section{REFERÊNCIAS}

ALEXY, R. Teoria dos direitos fundamentais. Tradução: Virgílio Afonso da Silva. 2. ed. São Paulo: Malheiros, 2017.

BRASIL. [Constituição (1988)]. Constituição da República Federativa do Brasil de 1988. Brasília, DF: Presidência da República, 1988. Disponível em: http://www.planalto.gov.br/ccivil_03/constituicao/constituicao.htm. Acesso em: 20 mar. 2021.

BRASIL. Lei no 9.394, de 20 de dezembro de 1996. Estabelece as diretrizes e bases da educação nacional. Brasília, DF: Presidência da República, 1996. Disponível em: http://www.planalto.gov.br/ccivil_03/leis//9394.htm. Acesso em: 20 mar. 2021.

CHAVES, E. M.; AMORIM, D. M. B. A interdisciplinaridade como princípio de formação docente: limites e possibilidades - o CSFP em questão. Educação, Porto Alegre, v. 32, n. 3, p. 316-325, 2009.

FREIRE, P. Papel da educação na humanização. Revista Paz e Terra, São Paulo, n. 9, p.123-132, 1969.

IPEA. Pandemia amplia desigualdade no sistema educacional, diz estudo do Ipea: falta de internet e de saneamento básico expõem disparidades estruturais nas escolas. ipea Instituto de Pesquisa Econômica Aplicada, [s. I.], 2020. Disponível em:

https://www.ipea.gov.br/portal/index.php?option=com_content\&view=article\&id=3606 9. Acesso em: 09 mar. 2021.

MACHADO, C.; ANDRADE, E. F. Democratização do direito à educação básica no Brasil: algumas ponderações. Cadernos de Pesquisa, São Luís, v. 28, n. 1, p. 3358, 2021.

OLIVEIRA, J. F.; LIBÂNEO, J. C.; TOSCHI, M. S. Educação escolar: políticas, estrutura e organização. São Paulo: Cortez, 2017.

PIOVESAN, F. Temas de direitos humanos. 10. ed. São Paulo: Saraiva, 2017.

SENA, M. C. et al. Mediação de conflito escolar como ferramenta de prevenção ao bullying: ação em saúde pública. Multitemas, Campo Grande, MS, v. 25, n. 60, p. $45-69,2020$.

SENHORAS, E. M. Coronavírus e educação: análise dos impactos assimétricos.

Boletim de Conjuntura, Boa Vista, ano 2, v. 2, n. 5, p. 1-11, 2020. 
UNESCO. COVID-19 resposta educacional: nota informativa - setor de educação: nota informativa $\mathrm{n}^{\circ} 7.1$ - abril de 2020. [S. I.]: UNESCO, 2020. Disponível em: https://unesdoc.unesco.org/ark:/48223/pf0000373275_por?posInSet=1\&queryld=f5e 77daf-4788-48e3-8d17-8e13b634dfa6. Acesso em: 09 mar. 2021.

UNICEF. Educação. UNICEF, [s. I.], 2020. Disponível em:

https://www.unicef.org/brazil/educacao. Acesso em: 30 mar. 2021.

SAVIANI, D. Sistema nacional de educação articulado ao Plano Nacional de Educação. Revista Brasileira de Educação, Rio de Janeiro, v. 15, n. 44, p. 380 393, 2010. 